\title{
Sodium Fluxes in Fresh-water Turtles '
}

\author{
WILLIAM A. DUNSON \\ Department of Zoology, The University of Michigan, Ann Arbor, Michigan, \\ and The Pennsylvania State University, Z University Park, Pennsylvania
}

\begin{abstract}
Fresh-water softshell turtles (Trionyx spinifer) showed net uptake of sodium from solutions as dilute as $5 \mu \mathrm{M}$. Chloride uptake could be accounted for by passive processes. There was no net uptake of potassium. Net sodium uptake was inhibited by low temperatures. Hibernation resulted in decreases in the sodium concentration and osmotic pressure of the plasma.

Influx and efflux of sodium in the fresh-water turtle Pseudemys scripta varied from 0.04 to $10.1 \mu$ moles $/(100$ g hour $)$. In hatchling turtles, the exchangeable sodium pool was $96 \%$ of the total sodium. The exchangeable pool was subdivided into at least two compartments, one rapidly and the other slowly exchanging. The latter compartment was 19 times larger than the former.

Pseudemys scripta, was found to have a system for active uptake of sodium. This involves the membranous lining of the pharynx, the cloacal bursae and the cloaca. Aside from the skin and the shell, these are the only tissues in contact with environmental water. The cloacal region accounted for 48 to $68 \%$ of the sodium influx rate.
\end{abstract}

Fresh-water turtles have encountered the same problems of ionic regulation faced by fresh-water fish and amphibians. In the latter the major problems, excess water intake and ion loss, have been counteracted in part by the formation of a copious dilute urine and the active uptake of sodium. Due to the impermeable appearance of reptilian skin, it was long believed that turtles would not need to take up sodium actively. Any extrarenal and renal losses of sodium were thought to be small enough to be made up in the food. This has not proved to be the case. Fresh-water softshell turtles (Trionyx spinifer) can actively obtain sodium from water containing as little as $5 \mu \mathrm{M}$ of this cation (Dunson, '64; Dunson and Weymouth, '65). Trionyx spinifer (Trionyx), however, has special problems of sodium balance because extensive respiratory surfaces in contact with the water facilitate sodium loss (Gage and Gage, 1886; Dunson, '60, '66; Girgis, '61). A more representative fresh-water turtle, Pseudemys scripta (Pseudemys), utilizes anaerobic metabolism while diving (Belkin, '63; Robin, Vester, Murdaugh and Millen, '64) and presumably avoids excess sodium loss across respiratory membranes. The purpose of this study was to investigate further the fluxes of sodium across the surfaces of fresh-water turtles. This included separate measurements of net flux, influx, efflux and the exchangeable sodium pool of the whole animal as well as investigations of isolated membranes suspected of being the sites of sodium uptake. Particular attention was devoted to examination of the transport capacities of the paired cloacal bursae (accessory bladders), the cloaca and the pharynx.

\section{MATERIALS AND METHODS}

Turtles were bought from commercial suppliers or caught in the vicinity of Ann Arbor, Washtenaw Co., Michigan. They were kept in tap water and fed frozen shrimp. Net ion fluxes were measured by placing the turtles in two liters of distilled water in covered aquaria and taking serial samples of the water. Sodium and potassium concentrations were measured by flame photometry (Coleman, model 21), and chloride concentration was determined with an Aminco Cotlove titrator (model 4-4420A). A Mechrolab vapor pressure osmometer, model 301A, was used to measure osmotic pressure. Conductivity of 0.15 $\mathrm{ml}$ water samples in a small chamber (cell constant 0.27) was measured with a Philips conductivity bridge (model PR9500). Turtles were weighed to the

\footnotetext{
1 This investigation was supported in part by grants 5T1-GM-989-03 and 1-F1-GM-18,741-01A1 from NIH, and NASA grants NGR-39-009-0i5 and Tr. 5994. Portions of this matexial were submitted to the University of Michigan in partial fulfilment of the requirements for a Ph.D. degree.

2 Present address.
} 
nearest $0.1 \mathrm{gm}$ on an Ohaus triple beam balance.

Sodium influx was measured in Pseudemys placed in $250 \mu \mathrm{M}$ sodium containing $\mathrm{Na}^{24} \mathrm{Cl}$. The influx of $\mathrm{Na}^{24}$ was monitored with a Nuclear Chicago model 186 scaler and sodium iodide crystal. The turtles were placed directly over the crystal in beakers. This method was $30 \%$ as efficient as counting the whole animal dissolved in nitric acid in a test tube inside the crystal. At least three measurements of influx were made over an 8- to 24-hour period. Influxes were linear during this time. Sodium efflux was measured in three Pseudemys hatchlings averaging $7.2 \mathrm{gm}$, after loading for 62 hours in $\mathrm{Na}^{22} \mathrm{Cl}$. Turtles were placed in tap water $(175 \mu \mathrm{M} \mathrm{Na})$ and allowed to equilibrate for 24 hours. For the next 53.1 days (two turtles) or 91.3 days (one turtle) the total activity of the body was measured with the sodium iodide crystal. The tap water bath $(300 \mathrm{ml})$ was changed each time a reading was taken (10-12 times).

The turtle and the loading solution were treated as a two compartment system. The following formula for computing the fluxes (Potts, personal communication) was employed.

Compartment 1 is always the compartment loaded at time 0 .

$$
\begin{aligned}
& \frac{C_{1 t}}{C_{10}}=\frac{N a_{1}}{N a_{1}+N a_{2}}+\frac{N a_{2}}{N a_{1}+N a_{2}} \cdot e^{-\lambda t} \\
& \mathrm{k}_{1}\left(\mathrm{Na} \mathbf{a}_{1}\right)=\operatorname{flux}_{1-2} \\
& k_{2}\left(\mathrm{Na}_{2}\right)=f l u x_{2-1} \\
& k_{1}\left(\mathrm{Na}_{1}\right)=k_{2}\left(\mathrm{Na}_{2}\right) \text { at equilibrium } \\
& \mathbf{k}_{1}+\mathbf{k}_{2}=\lambda \\
& \mathrm{C}_{10}=\text { counts in } 1 \text { at time o } \\
& \mathrm{C}_{1 \mathrm{t}}=\text { counts in } 1 \text { at time } t \\
& t=\text { elapsed time } \\
& \mathrm{Na}_{1}=\text { total } \mathrm{Na} \text { in } 1 \\
& \mathrm{Na}_{2}=\text { total } \mathrm{Na} \text { in } 2 \\
& k_{1}=\text { rate constant for flux } \mathbf{1}_{1-2} \\
& k_{2}=\text { rate constant for flux } 2-\pi
\end{aligned}
$$

This formula can be derived from that of Motais and Maetz ('65).

To separate the contributions of the mouth and cloacal region to the sodium influx rate in hatchling Pseudemys, influx was measured while the cloaca was open and closed. Cloacal closure was effected by suturing firmly with silk thread. In seven turtles the cloacal slit was closed before the measurement of the control influx rate, but in eight others not until afterwards.
The size of the exchangeable sodium pool was determined in six hatchling Pseudemys averaging $8.5 \mathrm{gm}$. The turtles were loaded for 47 to 56 hours in $\mathrm{Na}^{24} \mathrm{Cl}$ ( 250 $\mu \mathrm{M} \mathrm{NaCl}$ ). After loading, they were maintained in tap water $(175 \mu \mathrm{M} \mathrm{Na})$ for 20 to 30 hours to allow equilibration of the $\mathrm{Na}^{24}$ with the $\mathrm{Na}^{23}$ pool. At the end of this period, the total activity of each animal was measured with the scintillation counter. A blood sample was taken, and the body was dissolved in $15 \mathrm{ml}$ of concentrated nitric acid. The blood was centrifuged and the plasma obtained was counted in the scintillation counter. After decay of the $\mathrm{Na}^{24}, \mathrm{Na}^{23}$ content of the body and the plasma was measured by flame photometry. The size of the pool was calculated on the basis of the assumption that the specific activities of the plasma and the exchangeable sodium pool were equal.

Softshell turtles have been previously tested in the laboratory for long-term suppression by cold of active uptake of sodium, which produces appreciable net losses of this cation (Dunson and Weymouth, '65). A more natural test of this effect of temperature was performed in representatives of Trionyx that were hibernating in an outdoor pond in Manila, Arkansas. The turtles were collected from the bottom of the ice covered pond on February 1, 1965, and covered with wet cloths to retard evaporative water loss. Blood samples were taken by heart puncture 24 hours later and plasma sodium concentrations determined.

In Pseudemys the pharynx, cloacal bursae and cloaca were tested for active sodium transport. Turtles were killed by spinal section and membranes were removed and placed in an Ussing Cell (Ussing and Zerahn, '51) with a crosssectional area of $3.14 \mathrm{~cm}^{2}$. Reptilian Ringer's solution ( $150 \mathrm{mM} \mathrm{NaCl}, 4 \mathrm{mM}$ $\mathrm{KCl}, 2 \mathrm{mM} \mathrm{CaCl}, 2 \mathrm{mM}$ Sørensen buffer, $\mathrm{pH} 7.2$ ) was placed on both sides of the membrane. After an initial period of equilibration, the potential across the membrane was clamped at zero and sodium influx and efflux were determined by $\mathrm{Na}^{24}$ movement. Flux calculations were made with the same formula used for whole animal fluxes. 
The relation of pharyngeal membrane potentials and currents to outside sodium concentration was also measured in an Ussing Cell (area $0.785 \mathrm{~cm}^{2}$ ). Resistance was calculated from the potential and current. The external concentration of sodium was varied by placing distilled water on the mucosal side of the membrane and adding aliquots of sodium sulfate to the water. The serosal (internal) side of the membrane was bathed with sulfate turtle Ringer's solution (75.0 mM Na $2 \mathrm{SO}_{4}, 2 \mathrm{mM}$ $\mathrm{K}_{2} \mathrm{SO}_{4}, 2 \mathrm{mM} \mathrm{CaCl}{ }_{2} 2 \mathrm{mM}$ Sørensen buffer, pH 7.2).

\section{RESULTS}

\section{A. Net ion flux}

An initial net loss of sodium occurred when softshell turtles were placed in two liters of distilled water. This loss was followed by net uptake (fig. 1). The rate of the initial net loss of sodium per gram of body weight for eight turtles was inversely related to body weight (table 1 ). This initial loss of sodium was accompanied by an exponential loss of weight (fig. 1). The percentage weight loss per day appeared to be inversely related to body weight (fig. 2).

The variations in sodium and chloride concentration and osmotic pressure of two liters of medium containing a softshell turtle are shown in figure 3. After about 240 hours this turtle reached an equilibrium with respect to sodium $(20 \mu \mathrm{M})$. Eighty hours later, net loss of sodium developed again. When the external concentration was increased by adding sodium chloride, the turtle quickly reduced the sodium chloride concentration, but not to the previous equilibrium value. Net chloride flux was less than net sodium flux. Osmotic pressure of the medium increased during the experiment. Another softshell turtle weighing $434 \mathrm{gm}$ reacted in a similar way, although equilibrium was achieved at an external sodium concentration of 40 $\mu \mathrm{M}$. Conductivity of the medium increased in a linear fashion. A third turtle weighing $240 \mathrm{gm}$ came to sodium equilibrium in water containing a $5 \mu \mathrm{M}$ concentration of sodium (Dunson and Weymouth, '65, fig. 1). Conductivity of the medium increased throughout the experiment.

Two specimens of Chrysemys picta (Chrysemys) and one of Chelydra serpentina (Chelydra) were also tested for net sodium fluxes in two liters of distilled water. These species differed from Trionyx in their responses. The two Chrysemys showed no net uptake of sodium, both having a considerably decreased efflux or in-

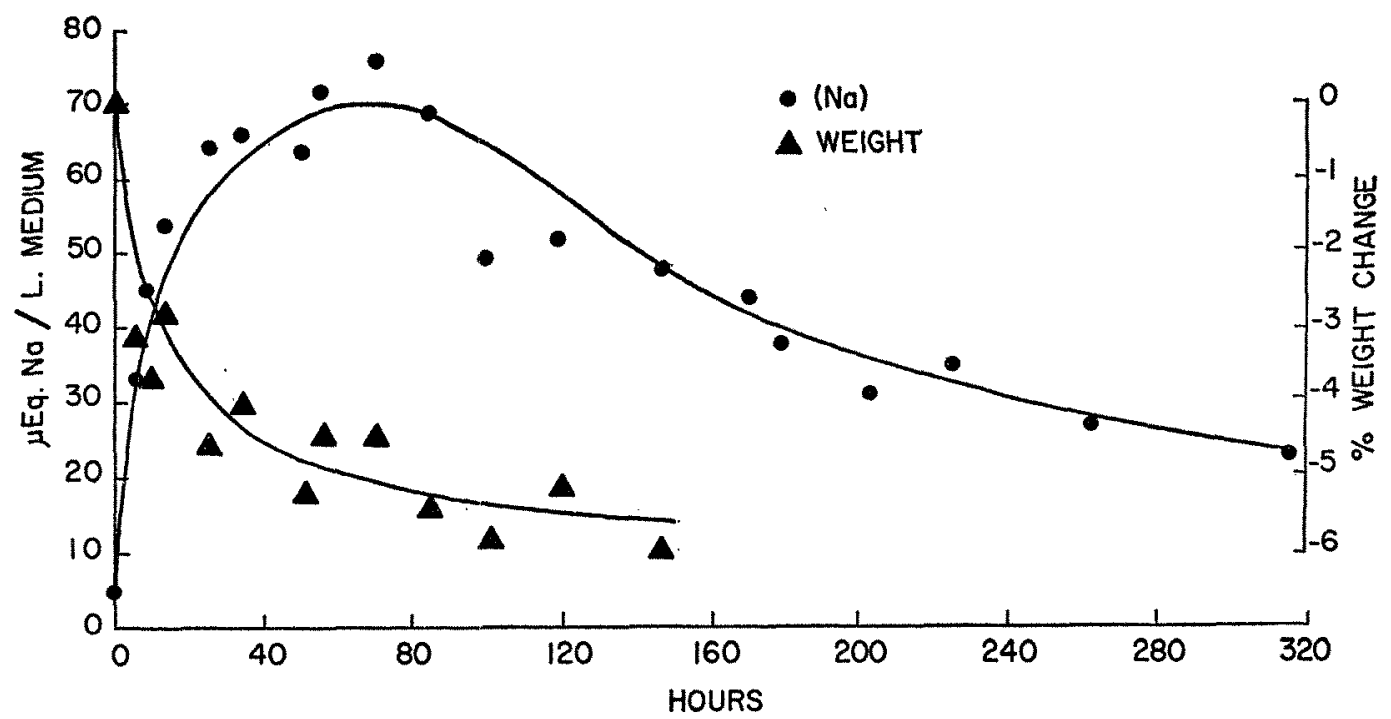

Fig. 1 Net sodium flux and weight change of Trionyx s. spinifer (184 gm) placed in two liters of distilled water (time 0 ) at $21 \mathrm{C}$. 


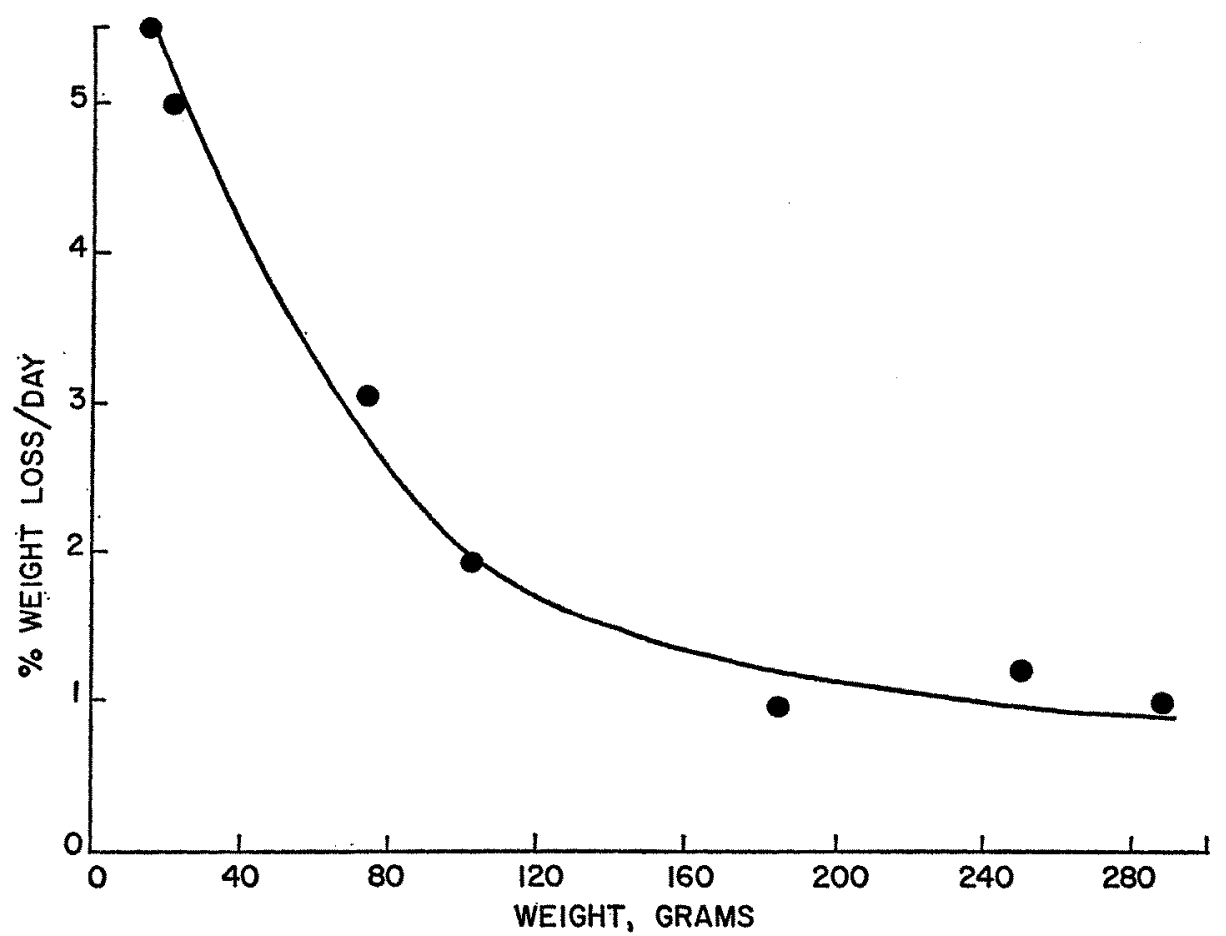

Fig. 2 Relation of the initial weight of Trionyx s. spinifer to the weight loss when placed in two liters of distilled water (time 0 ) at $21 \mathrm{C}$. Measurements of weight loss were made only during the first 200 hours, or less of the experiment.

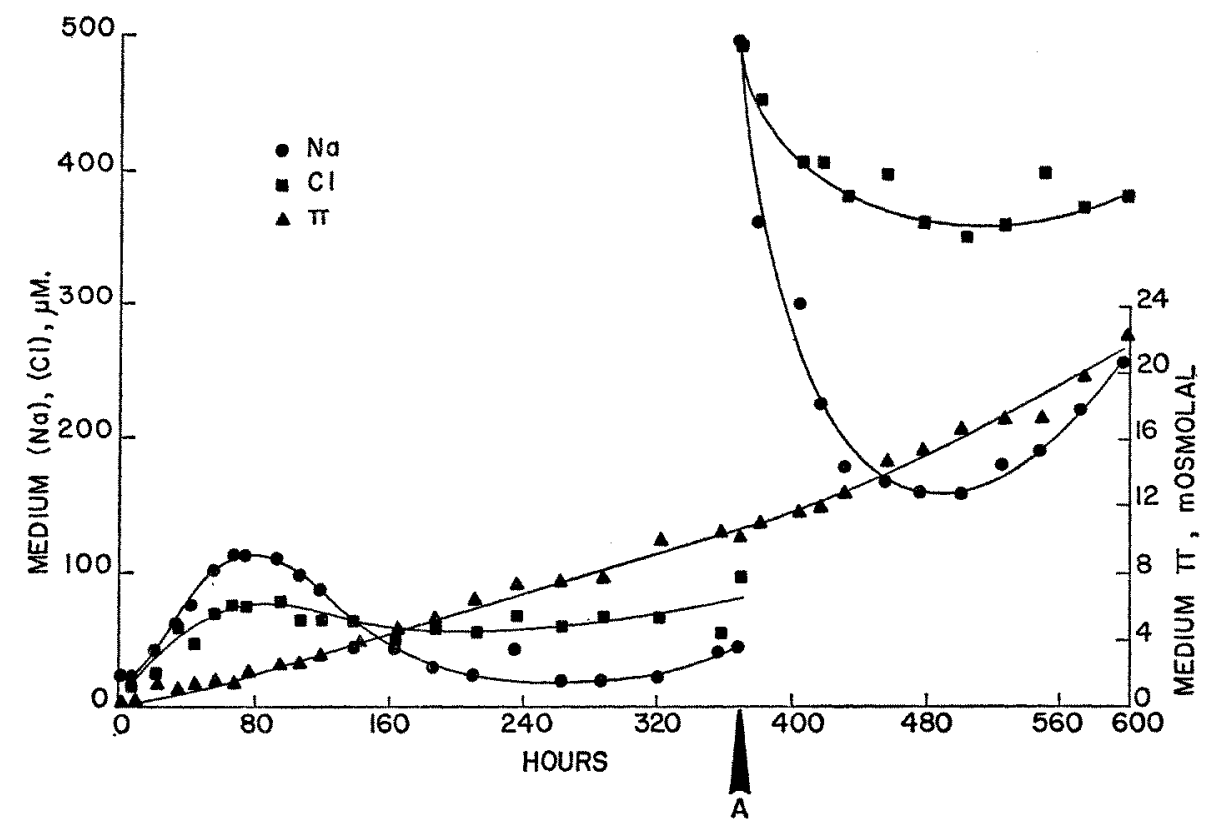

Fig. 3 Net sodium, chloride and total particle (osmotic pressure) fluxes of a Trionyx s. spinifer (492 gm) placed in two liters of distilled water (time 0 ) at $21 \mathrm{C}$. At point $\mathrm{A}$, sodium chloride was added to the medium. 
creased influx. The smaller turtle (117 $\mathrm{gm}$ ) came into balance (no net flux) with the medium at an external sodium concentration of about $63 \mu \mathrm{M}$. The larger turtle $(262 \mathrm{gm})$ still showed a net loss of sodium after 260 hours. The Chelydra tested ( $378 \mathrm{gm})$ had a lower rate of weight specific loss of sodium in distilled water than did Chrysemys. The net loss was linear for 260 hours. A comparison of the rate of net loss of sodium in Chrysemys and Chelydra was made for the first 100 hours after the turtles were placed in distilled water (table 1). For Trionyx, effluxes were calculated from the time at which the sodium concentration in the medium began to increase until the maximum was attained, which rarely was as long as 100 hours. The data in table 1 indicate that Chrysemys lost less sodium than Trionyx of the same weight. Chelydra certainly lost less sodium per unit weight than Trionyx, and most likely less than Chrysemys as well.

\section{B. Effect of cold on net sodium balance}

Plasma sodium concentrations of the ten Trionyx collected in Arkansas under conditions closely simulating natural hibernation varied from 74.0 to $108.0 \mathrm{mM}$ (mean, $94.6 \mathrm{mM}$ ). The direct relation between plasma sodium concentration and osmotic pressure of these turtles and others kept in artificial hibernation (Dunson and Weymouth, '65, table 1) is shown in fig-

TABLE 1

Initial net sodium loss from turtles in two liters of distilled water at $21^{\circ} \mathrm{C}$

\begin{tabular}{lcc}
\hline Species & Weight & $\begin{array}{c}\text { Net } \\
\text { sodium } \\
\text { loss }\end{array}$ \\
\hline Trionyx spinifer & gm & (100 g holes $)$ \\
& 73 & 5.1 \\
& 101 & 4.8 \\
& 184 & 1.3 \\
& 240 & 3.5 \\
& 315 & 1.3 \\
Chrysemys picta & 397 & 1.7 \\
& 434 & 0.8 \\
Chelydra serpentina & 492 & 0.5 \\
& 117 & 0.6 \\
& 262 & 0.5 \\
\hline
\end{tabular}

ure 4. Changes in sodium concentration without equivalent monovalent anions can account for $77 \%$ of the observed changes in osmotic pressure.

\section{Sodium influx and the sodium pool}

Rates of sodium influx among $24 \mathrm{Pseu-}$ demys varied considerably (range: 0.04 to 10.1 umoles $/ 100 \mathrm{~g}$ hour). Moreover, tenfold variations in influx occurred in the same turtle tested at different times. In the vast majority of cases, the rate of influx was constant for periods up to 60 hours. The total sodium content of six turtles (Pseudemys) in July, 1965, was 71 umoles/gm. In another group of six turtles (Pseudemys) measured in September, 1966, it was $79 \mu \mathrm{moles} / \mathrm{gm}$. The size of the exchangeable sodium pool was estimated for members of this latter group. Values ranging from 91 to $105 \%$ of the total body sodium were obtained. The average exchangeable sodium pool was $641 \mu$ moles for an $8.5 \mathrm{gm}$ turtle. This is approximately $96 \%$ of the total sodium present in the body. Thus it appears that $\mathrm{Na}^{24}$ can equilibrate with almost all of the $\mathrm{Na}^{23}$ in the body of a young turtle within three days. For the flux calculations, it has been assumed that the exchangeable pool is equal to the total amount of body sodium.

\section{Sodium efflux and the exchangeable pool}

Data on sodium efflux for three Pseudemys were plotted as the log of the per cent of original activity (cpm) in the body against time. Figure 5 illustrates the results for one turtle. A straight line was fitted by eye to the final portion of the function ( $B$ in fig. 5). This line, extrapolated back to zero time, was then subtracted from the initial nonlinear portion (A in fig. 5). The rate of efflux in these turtles is low enough so that the component $B$ of the flux can be read directly from the final linear portion of the curve. In a more typical case (Solomon, '49), the slope of component $B$ would decrease with time. Two subtractions would then be required to obtain the rate of exchange of the compartments.

In the three turtles tested, efflux from the exchangeable pool could be subdivided 


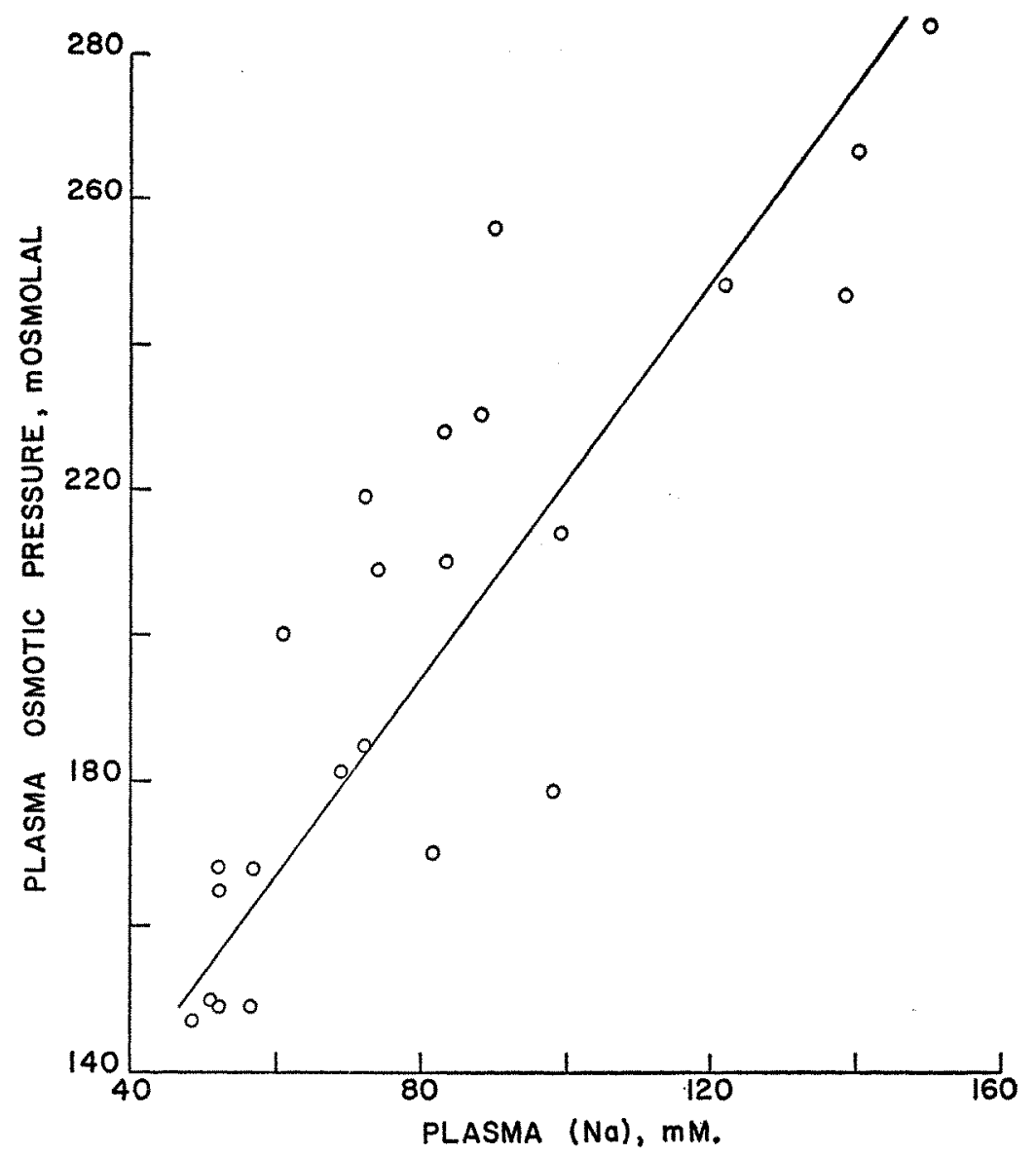

Fig. 4 The relation of plasma sodium concentration to the osmotic pressure of the plasma in Trionyx s. spinifer. Each point represents one animal.

into two pools or compartments. The smaller of the two compartments decreased in activity faster, although the rates of exchange of the two compartments were almost equal in one turtle. Thus compartment $C$ (fig. 5) may be called the fast compartment. The size of the fast compartment varied from 4.5 to $6.5 \%$ of the exchangeable sodium. This figure was obtained by comparing the activity (cpm) of the two compartments (fig. 5, lines B, C) at time zero. The efflux rate of the fast compartment varied from 0.26 to $0.88 \%$ / day of the total activity of the animal. In the three turtles studied, no radioactivity could be detected coming from the fast pool after 10 to 25 days.
The efflux rate of the slow compartment was 0.11 to $0.26 \%$ /day of the total activity. The pool size was 93.5 to $95.5 \%$ of the exchangeable pool. The biological halflife of the exchangeable pool, including fast and slow components, was 200, 250 and 540 days in three turtles. Total efflux rates in these turtles were $3.3,1.6$ and 3.3 umoles $\mathrm{Na} /(100 \mathrm{~g}$ hour) respectively. These values are within the range of the influx rates measured in other turtles.

\section{E. Cloacal and pharyngeal sites of sodium uptake}

Influx of normal animals was compared with the influx measured while the cloacal slit was artificially closed. Influx always 


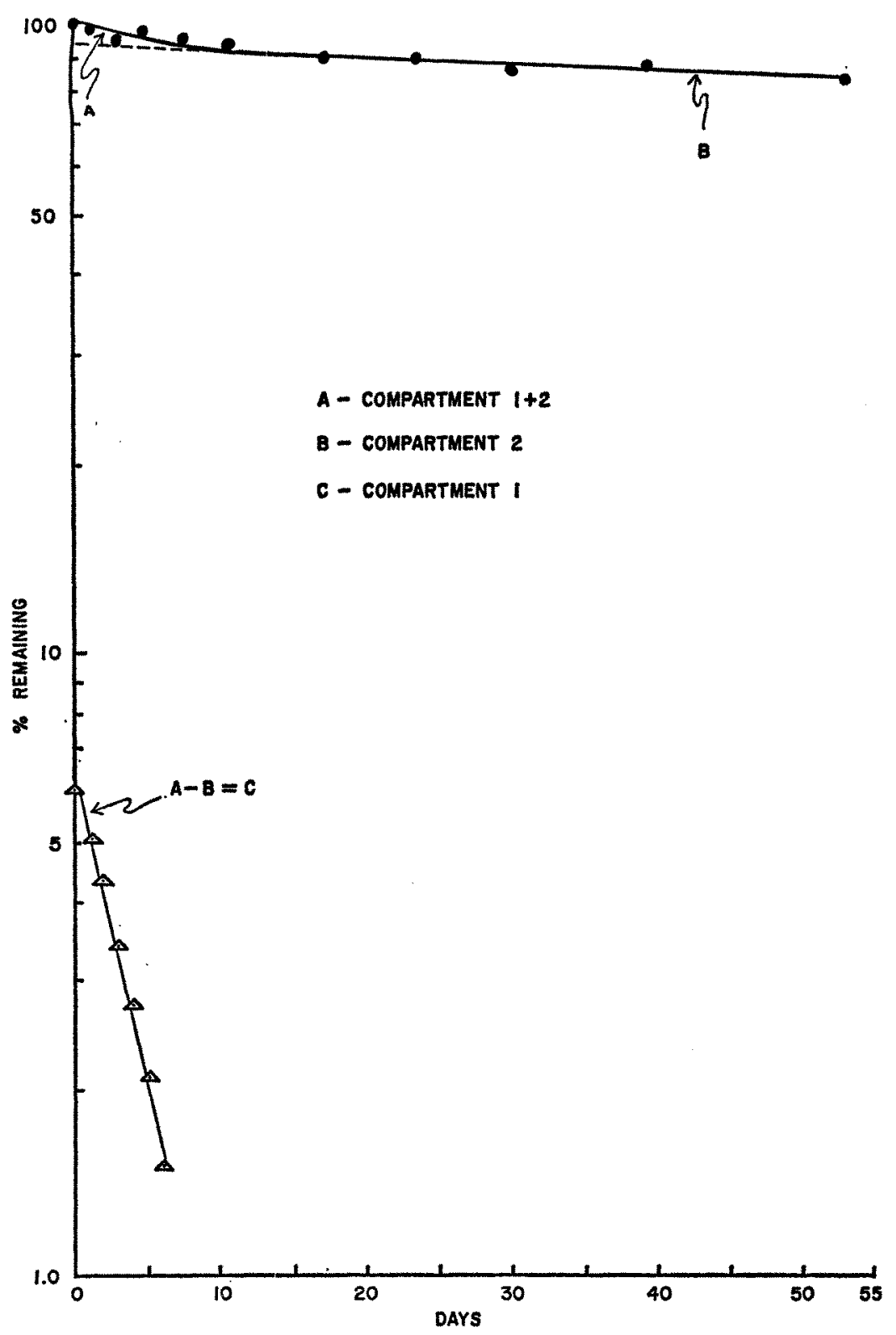

Fig. 5 Analysis of sodium efflux in Pseudemys scripta.

decreased after closure of the cloacal slit. The contribution of the cloacal region to total influx estimated in this fashion in eight Pseudemys was $68 \pm 14 \%$. If the cloacal slit was sutured shut at the beginning of the experiment and then subsequently opened, the influx always increased. The cloacal contribution estimated in this way in seven Pseudemys was $48 \pm 21 \%$ of the control influx rate. The reason for the difference between the two methods is not clear. Since uptake through the cloacal region accounted for no more than two-thirds of the sodium influx rate, 
a significant remainder must occur over other areas such as the mouth or the skin.

Figure 6 shows diagrammatically the anatomy of the urogenital tract in an adult male Pseudemys. The cloacal bursae or accessory bladders are quite large. However, the urinary bladder holds more fluid. Water entering the cloacal opening could conceivably come into immediate contact with the cloaca, cloacal bursae, rectum, or urinary bladder. In the present study, four out of nine adult Pseudemys examined had fluid in their cloacal bursae. When placed in phenol red solution, three adult Pseudemys which took up fluid had red dye only in the cloacal bursae and the cloaca. It was impossible to tell if the cloacal fluid was just leakage from the bursae. The bursae and the cloaca appear to be in free communication.

\section{F. Sodium flux across isolated pharynx, cloaca and cloacal bursae}

The inside (serosal) surface of all three membranes was positive (range 5-86 mv), and all demonstrated a net inward movement of sodium, which can be attributed to active transport (table 2 ). The amount of current calculated from the net movement of sodium and the observed short circuit current were similar. A paired data $t$ test on the calculated and observed current values revealed no significant difference between the two currents in

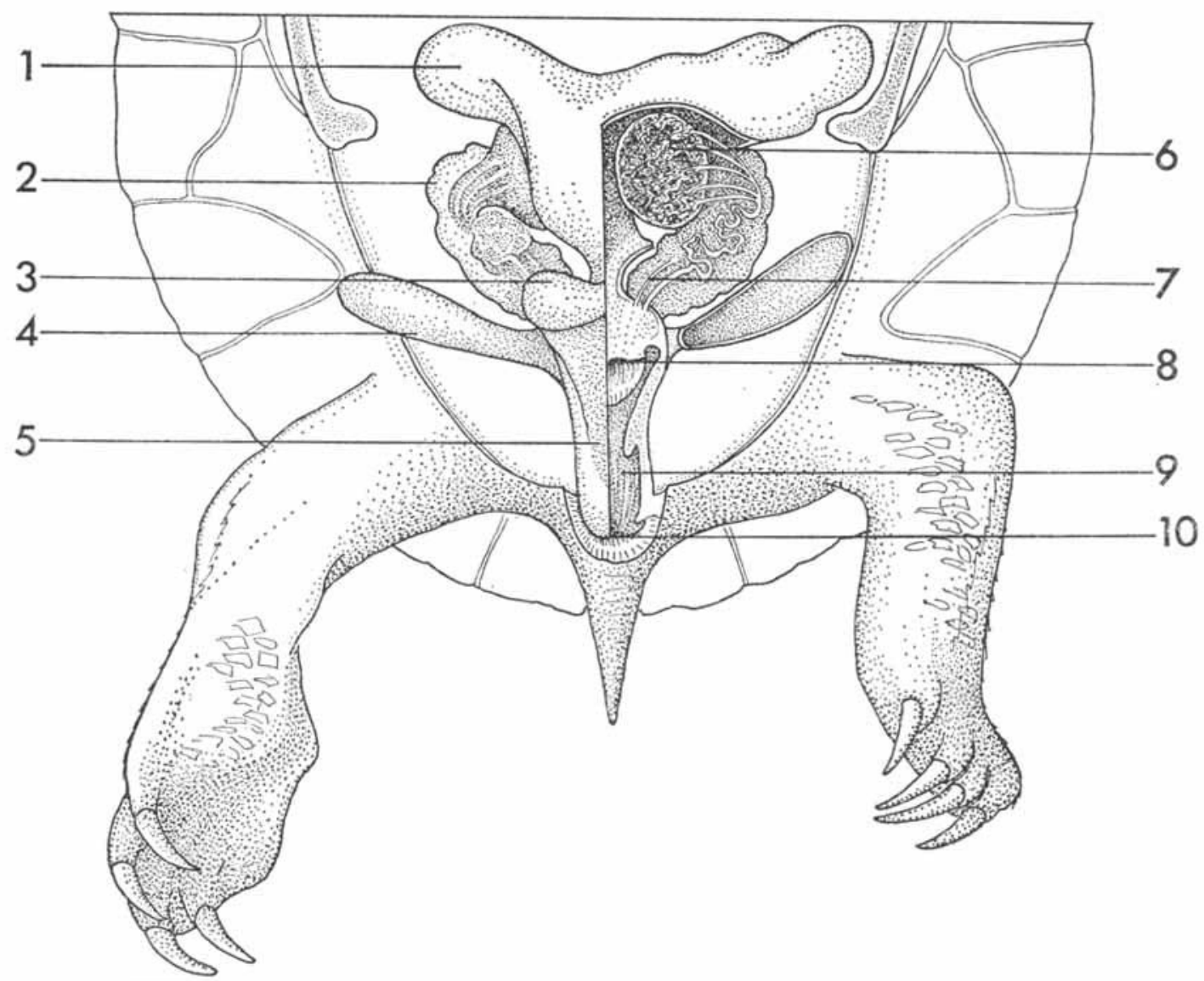

Fig. 6 Ventral diagrammatic view of the male urogenital system of Pseudemys scripta. Modified from Ashley ('62). 1, urinary bladder; 2, kidney; 3, bulb of corpora cavernosa; 4, cloacal bursa (accessory bladder); 5 , penis; 6 , testis; 7 , ureter; 8 , rectum; 9 , cloaca; 10 , anus. Drawing by $R$. D. Chambers. 
TABLE 2

Relation of net inward sodium flux to current across pharynx, cloacal bursa and cloaca of fresh-water turtles, Mean values in parentheses

\begin{tabular}{clccc}
\hline $\begin{array}{c}\text { Turtle } \\
\text { no. }\end{array}$ & Membrane & $\begin{array}{c}\text { Net inward } \\
\text { Na flux }\end{array}$ & $\begin{array}{c}\text { Calculated } \\
\text { current }\end{array}$ & $\begin{array}{c}\text { Observed } \\
\text { current }\end{array}$ \\
\hline & & $\begin{array}{c}\mu m o l e s / \\
\left(\mathrm{cm}^{2} \text { hour }\right)\end{array}$ & $\mu a m p s / \mathrm{cm}^{2}$ & $\mu a m p s / \mathrm{cm}^{2}$ \\
19 & Pharynx ${ }^{2}$ & 0.722 & 19.4 & 13.0 \\
20 & Pharynx & 0.663 & 17.8 & 16.9 \\
23 & Pharynx & 0.595 & 16.0 & 12.9 \\
68 & Pharynx & 0.315 & 8.5 & 17.2 \\
& & & $(15.4)$ & $(15.0)$ \\
67 & Cloacal bursa & 0.234 & 6.3 & 2.8 \\
70 & Cloacal bursa & 0.215 & 5.8 & 7.5 \\
74 & Cloacal bursa & 0.882 & 23.6 & 1.7 \\
76 & Cloacal bursa & 0.608 & 14.4 & $(12.9$ \\
& & & $(12.5)$ & 8.7 \\
77 & Cloaca & 0.305 & 7.2 & 14.7 \\
79 & Cloaca & 0.417 & 11.2 & 15.3 \\
82 & Cloaca & 0.576 & 15.5 & 29.4 \\
84 & Cloaca & 1.17 & 31.4 & $(17.0)$ \\
\hline
\end{tabular}

1 Graptemys sp., all others Pseudemys scripta.

pharynx $(P>0.9)$, cloacal bursa $(P>$ $0.9)$ and cloaca $(P>0.6)$. It is likely that sodium is the only ion moving across the pharynx, cloacal bursa and cloaca in a net fashion under these conditions. Net sodium movements in all three membranes were similar in extent. The total relative areas of these membranes in the body have not been measured, but the cloacal bursae and the cloaca together probably include a greater surface area than the pharynx. The in vivo measurements previously indicated that 48 to $68 \%$ of the sodium influx rate was attributable to the cloacal region.

\section{G. The isolated pharynx and outside sodium concentration}

With Ringer's solution on both sides of the Trionyx pharynx, the mucosa was negative with respect to the serosa. When distilled water was placed on the mucosal side, the potential reversed and the current almost disappeared. Addition of small amounts of sodium salts to the distilled water on the mucosal side resulted in a rise in potential and current until the mucosa again became negative. In several cases the mucosa was negative with respect to the serosa even at the lowest concentration of external sodium tried (fig. 7). This was true for three out of eight Trionyx tested. Zero potential points for the other five Trionyx varied from 0.3 to $10.0 \mathrm{mM}$ sodium, when sodium sulfate was being added to the mucosal side and sulfate Ringer's solution was present on the serosal side. With further additions of sodium to the medium on the mucosal side, the potential and current rose until a saturation point at 10 to $80 \mathrm{mM}$ sodium was reached. Current and potential were related directly and resistance inversely to mucosal sodium concentration.

\section{DISCUSSION}

All fresh-water turtles that have been tested have shown some evidence of a system for sodium uptake. Chelydra showed large pharyngeal and cloacal potentials and short circuit currents when electrolyte depleted (Dunson and Weymouth, '65). In distilled water, Chelydra of a given weight loses sodium more slowly than Trionyx and Chrysemys of similar size (table 1). Chelydra and Chrysemys did not show net sodium uptake in this study. All Trionyx placed in distilled water showed some net uptake of sodium after an initial loss, although the extent of uptake varied considerably. From the data presented on net sodium flux (figs. 1, 3), it is clear that softshell turtles (Trionyx) can maintain sodium balance by active 


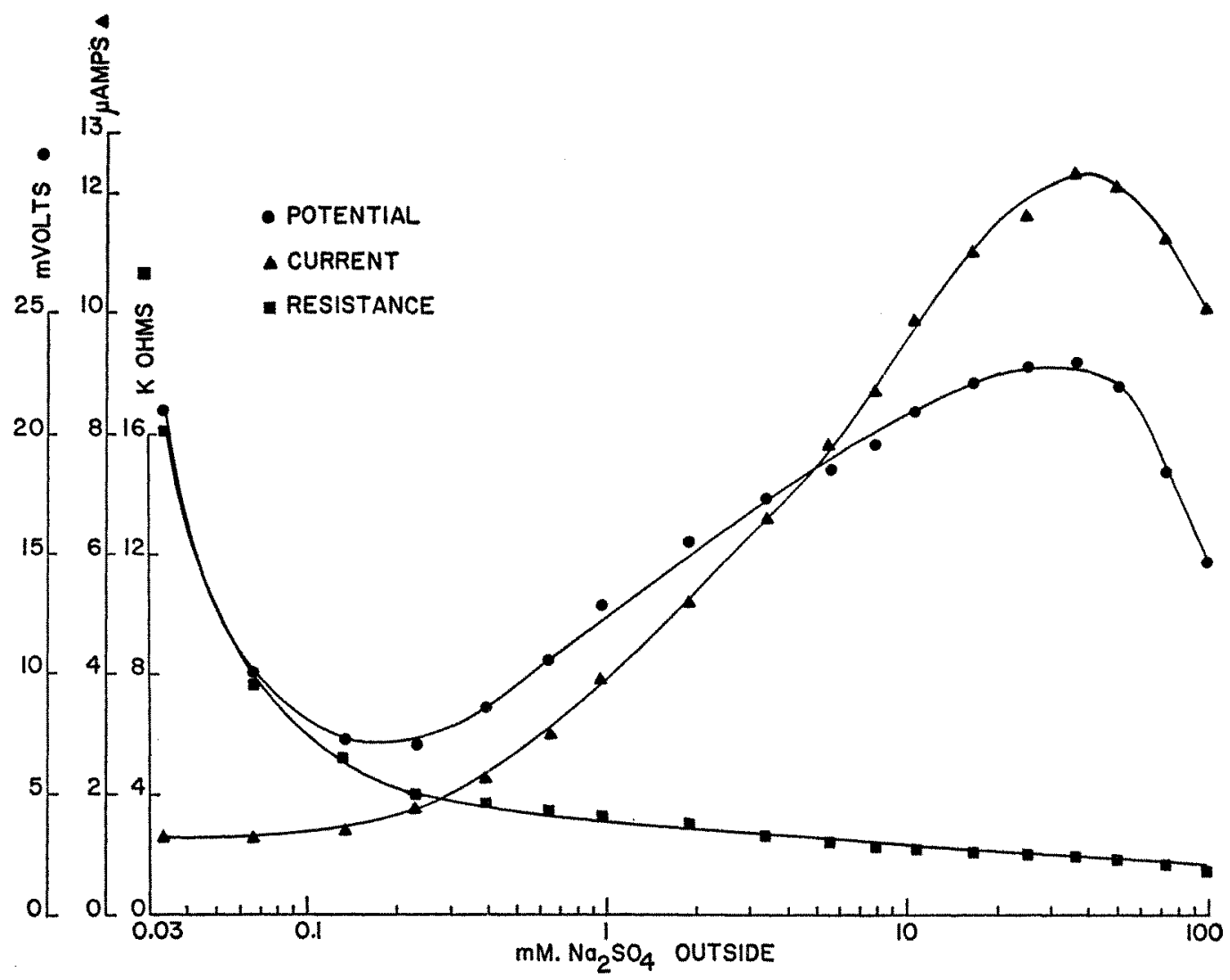

Fig. 7 The effect of external sodium sulfate concentration on the potential, current, and resistance of an isolated pharynx from Trionyx s. spinifer.

uptake alone. The failure of chloride to follow sodium in equivalent quantities indicated that other anions, possibly bicarbonate, were involved in the maintenance of the electrical equilibrium. It does not appear that chloride is being taken up actively, but that possibility cannot be ruled out. No uptake mechanism for potassium was evident. However this ion can be readily obtained from the food.

Softshell turtles placed in distilled water usually underwent a slight gain and then a large decline in weight. However an initial gain was not always observed (fig. 1). When it did occur, it probably was the result of water influx from the environment. The subsequent weight decrease may be explained by urinary water loss which would tend to conteract the effects of solute loss and water influx on the concentration of the body fluids. The sodium concentration of bladder urine of 11 softshell turtles varied from 70 to 840 $\mu \mathrm{M}$. More data are needed to clarify the relation between body weight and the amount of solute and water loss.

The minimum equilibrium concentration for crayfish (Astacus) varies from 20 to $90 \mu \mathrm{M}$ sodium (Shaw, '59), whereas in frogs it is about $10 \mu \mathrm{M}$ chloride (Krogh, '39). Sodium is taken up by the gills of eels when the external concentration exceeds $100 \mu \mathrm{M}$ (Chester Jones, Philips and Bellamy, '62). In Trionyx this equilibrium concentration varied from 5 to about 40 $\mu \mathrm{M}$. Only at the lower end of the range was it maintained without significant net change during the whole experiment. This is seen in a comparison of the course of net sodium flux in figure 3 of this report with that in figure 1 of Dunson and Weymouth ('65). The turtle in figure 3 was 
probably in more favorable sodium balance. Thus it did not maintain the apparent equilibrium ( $20 \mu \mathrm{M}$ sodium) that it attained. Salt depletion of this individual might well have decreased the apparent lowest equilibrium concentration. The turtle shown in figure 1 of Dunson and Weymouth ('65) rigidly maintained the same medium concentration ( $5 \mu \mathrm{M})$ despite salt loading. Salt loading of the turtle in figure 3 resulted in a net loss of sodium. Thus the minimum equilibrium concentration seems to be rather constant among individual turtles (Trionyx). Some of the variation that occurs is probably due to insufficient salt depletion of the animal before testing.

Dunson and Weymouth ('65) showed that net sodium uptake in Trionyx was supressed by cold. Moreover they also observed that turtles kept in cold tap water $\left(7.4^{\circ}-15.0^{\circ} \mathrm{C}\right)$ had considerably lower plasma sodium concentrations than control animals at $25^{\circ} \mathrm{C}$. None of the Trionyx kept in cold running tap water survived the winter. Since these turtles obviously do survive the winter in nature, some other factors must be operative. The hibernaculum may provide a means of restricting ion loss, or the permeabilities of the captive animals may have been enhanced in some way. To take blood from a naturally hibernating population was impossible, but turtles hibernating in a large pond at a turtle farm in Arkansas provided a satisfactory substitute. By the beginning of February these turtles showed definite depression of plasma sodium concentrations (mean $94.6 \mathrm{mM}$ ), but they were still far above the lethal limit (about $52 \mathrm{mM}$ ). Of course the Arkansas turtles were exposed to cold for shorter periods than those kept in artificial hibernation in tap water in Michigan, so this result might have been expected. The lowering of plasma sodium concentration results from the inhibition of sodium uptake from the environment and presumably from the renal filtrate by low temperatures. Tolerance of low concentrations of electrolytes in the plasma appears to be an adaptation to life in areas with cold winters. That the major osmotic stress in plasma comes from electrolyte loss is indicated by figure 4 . As mentioned previously, about $77 \%$ of the total plasma osmotic pressure change can be accounted for simply on the basis of sodium. Softshell turtles are less permeable to chloride than sodium (fig. 3 ), and chloride loss could account for the remainder of the osmotic pressure decrease. It is likely that some compensatory mechanism has come into play to retard the fall in osmotic pressure, since sodium loss should be followed by a commensurate loss of anions. This would result in a larger plasma osmotic pressure drop than that observed. Hutton and Goodnight ('57) found that the plasma sodium concentration fell markedly during hibernation in Terrapene and Pseudemys. The Pseudemys were in water only part of the winter, and the Terrapene were kept dry. The cause of sodium loss under these conditions is unknown, but it appears different from that in softshell turtles.

The influx of sodium in Pseudemys appeared to be a linear function of time (up to 60 hours) on an arithmetic plot. According to the data on efflux, at least two compartments are present. A fast and a slow linear phase are detectable on a semilogarithmic plot. The exchangeable sodium pool in hatchling Pseudemys was $96 \%$ of the total sodium present. In humans, the proportion of total sodium which is exchangeable falls from almost $100 \%$ in infancy to $66 \%$ in adulthood (Forbes, '62). The fast pool in turtles represented 4.5 to $6.5 \%$ of the exchangeable sodium, and the slow pool 93.5 to $95.5 \%$. Until more work is done, it is impossible to assign these pools to any given tissue or fluid.

In fresh-water fish the influx and efflux of sodium are on the order of $1 \%$ of the exchangeable sodium per hour. In flounders weighing 60 to $390 \mathrm{gm}$ this amounts to $44 \mu$ moles sodium $/(100 \mathrm{~g}$ hour) (Motais and Maetz, '64). In larval and adult salamanders (Ambystoma tigrinum) weighing about $13 \mathrm{gm}$ and adapted to pond water, influx and efflux of sodium were about $13 \mu \mathrm{moles} /(100 \mathrm{gm}$ hour) (Alvarado and Kirschner, '63). Sodium influx in Pseudemys varied from 0.04 to 10.1 $\mu$ moles $/(100 \mathrm{gm}$ hour $)$. The maximum rate of net chloride uptake in the crayfish (Astacus) was $15 \mu$ moles/(100 gm hour) (Krogh, '38). In the frog it was 81 umoles chloride/(100 gm hour), and in the sal- 
mon $30 \mu$ moles chloride/(100 gm hour) (Krogh, '37, '38). The minimum equilibrium concentration for salt uptake is usually less than $1 \mathrm{mM}$ sodium chloride for fresh-water animals (Potts and Parry, '64). This value in softshell turtles is 5 to 40 $\mu \mathrm{M}$ sodium. The frog with a minimum chloride equilibrium concentration of 10 $\mu \mathrm{M}$ is the only animal with a similarly low value. Thus in comparison with the uptake systems of other fresh-water animals, turtles have a low minimum equilibrium concentration and a low rate of uptake of sodium.

Musacchia and Chladek ('61) have confirmed previous reports that water is taken into the cloacal bladders (bursae) of freshwater turtles. Musacchia and Chladek ('61), Smith and James ('58), and Smith and Nickon ('61) postulated that the cloacal bursae participate in aquatic respiration, just as the pharynx of the softshell turtle does (Dunson, '60). In Pseudemys this cannot be true, since respiration is almost completely anaerobic during a dive (Belkin, '63; Robin, Vester, Murdaugh and Millen, '64). The present study indicates that these bursae in fact function in sodium uptake in this turtle.

This study has demonstrated that freshwater turtles are not divorced from the environment by ionic impermeability. The total ion fluxes across their body surfaces are relatively small, but specialized membranes are present which help to regulate the body fluid composition.

\section{ACKNOWLEDGMENTS}

I am deeply indebted to Dr. W. R. Dawson for his advice and encouragement. Dr. Richard L. Malvin, Dr. W. T. W. Potts, and Dr. C. J. Shellabarger were very helpful during various stages of this work.

\section{LITERATURE CITED}

Alvardo, R. H., and L. B. Kirschner 1963 Osmotic and ionic regulation in Ambystoma tigrinum. Comp. Biochem. Physiol., 10: 55-67.

Ashley, L. M. 1962 Laboratory Anatomy of the Turtle. W. C. Brown Co., Dubuque, Iowa, p. 40.

Belkin, D. A. 1963 Importance of aquatic respiration in the diving ability of turtles. Fed. Proc., 22: 634.

Chester Jones, I., J. G. Philips and D. Bellamy 1962 Studies on water and electrolytes in cyclostomes and teleosts with special reference to Myxine glutinosa L. (the hagfish) and Anguilla anguilla (the Atlantic eel). Gen. Comp. Endocrinol., Suppl., 1: 36-47.
Dunson, W. A. 1960 Aquatic respiration in Trionyx spinifer asper. Herpetologica, 16: 277283.

1964 Sodium balance in the softshell turtle, Trionyx s. spinifer. Am. Zool., $4: 390$.

Dunson, W. A., and R. D. Weymouth 1965 Active uptake of sodium by softshell turtles. Science, 149: 67-69.

Dunson, W. A. 1966 Relation of the rate of hyoid movement to body weight and temperature in diving soft-shell turtles. Comp. Biochem. Physiol., 19: 597-601.

Forbes, G. B. 1962 Sodium. In: Mineral Metabolism. C. L. Comar and F. Bronner, eds. V. 2B Academic Press, pp. 2-72.

Gage, S. H., and S. P. Gage 1886 Aquatic respiration in soft-shelled turtles (Amyda mutica and Aspidonectes spinifer): A contribution to the physiology of respiration in vertebrates. Proc. A.A.A.S., 34: 316-318.

Girgis, S. 1961 Aquatic respiration in the common Nile turtle Trionyx triunguis (Forskal). Comp. Biochem. Physiol., 3: 206-217.

Hutton, K. E., and C. J. Goodnight 1957 Variations in the blood chemistry of turtles under active and hibernating conditions. Physiol. Zool., 30: 198-207.

Krogh, A. 1937 Osmotic regulation in the frog (Rana esculenta) by active absorption of chloride ions. Skand. Arch. Physiol., 76: 60-73.

1938 The active absorption of ions in some fresh-water animals, $Z$. vergl. Physiol., 25: 235-250.

1939 Osmotic Regulation in Aquatic 154-169.

Motais, R, and J. Maetz 1964 Action des hormones neurohypophysaires sur les éxchanges de sodium (Mesurés a l'aide du radio-sodium $\mathrm{Na}^{24}$ ) chez un téléostéen euryhalin: Platichthys flesus L. Gen. Comp. Endocrinol., 4: 210-224.

Musacchia, J. X., and M. I. Chladek 1961 Investigation of the cloacal bladder in turtles. Am. Zool., 1: 376.

Potts, W. T. W., and G. Parry 1964 Osmotic and Ionic Regulation in Animals. The Macmillan Co., New York, pp. 164-224.

Robin, E. D., J. W. Vester, H. V. Murdaugh and J. E. Millen 1964 Prolonged anaerobiosis in a vertebrate: anaerobic metabolism in the fresh-water turtle. J. Cell. and Comp. Physiol., 63: $287-297$.

Shaw, J. 1959 The absorption of sodium by the crayfish, Astacus pallipes Lereboullet. I. The effect of external and internal sodium concentrations. J. Exp. Biol., 36: 126-144.

Smith, H. M., and L. F. James 1958 The taxonomic significance of cloacal bursae in turtles. Trans. Kans. Acad. Sci., 61: 86-96.

Smith, H. M., and D. C. Nickon 1961 Preliminary experiments on the role of the cloacal bursae in hibernating turtles. Nat. Hist. Misc., 178: 1-8.

Solomon, A. K. 1949 Equations for tracer experiments. J. Clin. Invest., 28: 1297-1307.

Ussing, H. H., and K. Zerahn 1951 Active transport of sodium as the source of electric current in the short circuited isolated frog skin. Acta Physiol. Scand., 23: 110-127. 